Morphology and microstructure evolution of Ti-50 at.\% Al cathodes during cathodic arc deposition of Ti-Al-N coatings

Bilal Syed, Jianqiang Zhu, Peter Polcik, Szilard Kolozsvari, Greger Håkansson, Lars Johnson, Mats Ahlgren, Mats Jöesaar, and Magnus Odén

Citation: Journal of Applied Physics 121, 245309 (2017); doi: 10.1063/1.4990425

View online: http://dx.doi.org/10.1063/1.4990425

View Table of Contents: http://aip.scitation.org/toc/jap/121/24

Published by the American Institute of Physics

\section{AP| Journal of AlPplied Physics}

Save your money for your research.

It's now FREE to publish with us no page, color or publication charges apply.
Publish your research in the

Joumal of Applied Physics

to claim your place in applied

physics history. 


\title{
Morphology and microstructure evolution of Ti-50 at.\% Al cathodes during cathodic arc deposition of Ti-Al-N coatings
}

\author{
Bilal Syed, ${ }^{1}$ Jianqiang Zhu, ${ }^{1}$ Peter Polcik, ${ }^{2}$ Szilard Kolozsvari, ${ }^{2}$ Greger Håkansson, ${ }^{3}$ \\ Lars Johnson, ${ }^{4}$ Mats Ahlgren, ${ }^{4}$ Mats Jöesaar,,${ }^{1,5}$ and Magnus Odén ${ }^{1}$ \\ ${ }^{1}$ Nanostructured Materials, Department of Physics, Chemistry, and Biology (IFM), Linköping University, \\ SE-581 83 Linköping, Sweden \\ ${ }^{2}$ PLANSEE Composite Materials GmbH, DE-86983 Lechbruck am See, Germany \\ ${ }^{3}$ Ionbond Sweden AB, Box 1161, SE-58111 Linköping, Sweden \\ ${ }^{4}$ Sandvik Coromant, 12680 Stockholm, Sweden \\ ${ }^{5}$ SECO Tools AB, SE-737 82 Fagersta, Sweden
}

(Received 3 May 2017; accepted 14 June 2017; published online 29 June 2017)

Today's research on the cathodic arc deposition technique and coatings therefrom primarily focuses on the effects of, e.g., nitrogen partial pressure, growth temperature, and substrate bias. Detailed studies on the morphology and structure of the starting material—-the cathode—during film growth and its influence on coating properties at different process conditions are rare. This work aims to study the evolution of the converted layer, its morphology, and microstructure, as a function of the cathode material grain size during deposition of Ti-Al-N coatings. The coatings were reactively grown in pure $\mathrm{N}_{2}$ discharges from powder metallurgically manufactured Ti-50 at. $\%$ $\mathrm{Al}$ cathodes with grain size distribution averages close to $1800,100,50$, and $10 \mu \mathrm{m}$, respectively, and characterized with respect to microstructure, composition, and mechanical properties. The results indicate that for the cathode of $1800 \mu \mathrm{m}$ grain size the disparity in the work function among parent phases plays a dominant role in the pronounced erosion of $\mathrm{Al}$, which yields the coatings rich in macro-particles and of high $\mathrm{Al}$ content. We further observed that a reduction in the grain size of Ti-50 at.\% Al cathodes to $10 \mu \mathrm{m}$ provides favorable conditions for self-sustaining reactions between $\mathrm{Ti}$ and $\mathrm{Al}$ phases upon arcing to form $\gamma$ phase. The combination of self-sustaining reaction and the arc process not only result in the formation of hole-like and sub-hole features on the converted layer but also generate coatings of high $\mathrm{Al}$ content and laden with macro-particles. Published by AIP Publishing. [http://dx.doi.org/10.1063/1.4990425]

\section{INTRODUCTION}

Cathodic arc deposition is the quotidian PVD technique used to deposit hard coatings on cutting tools. This technique owes its expedience to the fact that the metal plasma formed during the process is highly ionized and dense. ${ }^{1}$ It begets good adhesion, high deposition rates, and dense coatings with compressive stress, ${ }^{2}$ which result in superior mechanical properties. ${ }^{3}$

The demands for higher cutting speeds during turning and milling operations require the coatings on cutting tools to withstand extreme and harsh conditions of high temperatures and pressures, which has motivated extensive research on multinary ceramic materials. For example, detailed understanding and abundant research material on $\mathrm{Ti}-\mathrm{Al}-\mathrm{N},{ }^{4} \mathrm{Zr}$ $\mathrm{Al}-\mathrm{N},{ }^{5}$ Ti-Si-N, ${ }^{6}$ etc., are readily available. Current research in this field has mainly been directed to tailor and understand the optimum microstructure by compositional variance. These multinary ceramic coatings are generally grown by using powder metallurgically produced multiphase cathodes, such as $\mathrm{Ti}-\mathrm{Al},{ }^{7} \mathrm{Zr}-\mathrm{Al},{ }^{8}$ Ti-Si, ${ }^{9}$ etc., arced in the presence of the reactive gas $\mathrm{N}_{2}$.

The perpetual existence of cathode spot(s) on the cathode surface is the very essence of the cathodic arc deposition process. In addition, the cathode spots dynamics can be influenced by, e.g., the microstructure of the cathode, which in turn may lead to changes in the microstructure of the coatings and, hence, also of its properties. ${ }^{9}$ Depending on cathode material, the electron temperatures between 2 and $5 \mathrm{eV}$ have been reported in the vicinity of cathode spots. ${ }^{10}$ The presence of such high electron temperatures, in proximity to the cathode surface, modifies its microstructure to a depth of several micrometers to form a converted layer. ${ }^{11}$

Most investigations on how to control coating microstructure and composition by manipulating the cathodic arc process are chiefly focused on the aspects of ambient gas pressure, ${ }^{12}$ bias voltage, ${ }^{13}$ deposition temperature, ${ }^{14}$ and magnetic steering ${ }^{15}$ of the cathode spot. However, the influence of the microstructure of the cathode on the synthesis of coating, their microstructure, and composition is almost never considered. Although the interplay of multiple phases in the cathode, the reactive gas, and the localized ultrahigh temperatures due to the transient nature of the cathode spots causes intermixing of the parent phases and the formation of new phases in the converted layer. In-depth knowledge of such mechanisms is needed for a comprehensive understanding of the arc deposition process and perhaps a mean to control the microstructure and composition of arc deposited coatings. This work focuses on the evolution of the converted layer on the cathode surface, its morphology, and microstructure, as a function of the Ti-50 at.\% $\mathrm{Al}$ cathode 
material, with the average grain size distribution ranging between 10 and $1800 \mu \mathrm{m}$, during the arc deposition of TiAl-N coatings. In addition, the effect of cathode material grain size on coating microstructure, composition, and mechanical properties is discussed.

\section{EXPERIMENTAL DETAILS}

Classified by different average grain sizes distributions, four grades of titanium-aluminum with equal atomic percentage were used in this study. The average grain sizes were $1800,100,50$, and $10 \mu \mathrm{m}$ and they were labeled as $1800 \mu \mathrm{m}$-grade, $100 \mu \mathrm{m}$-grade, $50 \mu \mathrm{m}$-grade, and $10 \mu \mathrm{m}$ grade, respectively. Monosized powder mixtures of $\mathrm{Ti}$ and Al were prepared by sieving to the right grain size and used as starting material during cathode manufacturing. All four grades were fabricated in the same manner, i.e., densification of the powder mixture by pressing and forging followed by solid state sintering at $400{ }^{\circ} \mathrm{C}$. This fabrication route resulted in a solid material with a density greater than $99.7 \%$ of theoretical density and below $300 \mu \mathrm{g} / \mathrm{g}$ of oxygen content.

In order to study the arc events on the virgin material, pieces with dimensions $1.5 \times 1.5 \times 0.5 \mathrm{~cm}^{3}$ were cut by a diamond blade from all four grades. These pieces were then polished to a mirror like finish by following the series of grinding, lapping, and polishing steps. The pieces were then cleaned in an ultrasonic ethanol bath. Each piece was fastened with electrically conducting silver containing glue on the surface of a dummy cathode [shown in Fig. 1(a)]. The triggering event serves a dual purpose, one being the initiation of the arc and the other being that the mechanical force imparted by the trigger on the piece breaks free the established electrical contact between the piece and the dummy cathode. This ensures that the arc traverses the surface of the piece only once (single trigger event). An industrial arc chamber (Metaplas MZR323) was used for all the experiments. The parameters used during the arcing of the pieces were $2.0 \times 10^{-6} \mathrm{~Pa}$ base pressure, $4.5 \mathrm{~Pa}$ nitrogen pressure, and $80 \mathrm{~A}$ arc current.

To capture the surface state after multiple arcing events (steady state arcing) and to analyze differences in the resulting coatings, full sized circular cathodes having a diameter of $63 \mathrm{~mm}$ were also made from all four grades. These cathodes were arced in $\mathrm{N}_{2}$ (reactive) ambience with the parameters of $2.0 \times 10^{-6} \mathrm{~Pa}$ base pressure, $4.5 \mathrm{~Pa} \mathrm{~N}_{2}$ pressure, $-30 \mathrm{~V}$ bias voltage, $75 \mathrm{~A}$ arc current, $300{ }^{\circ} \mathrm{C}$ process temperature, and a constant evaporation time is achieved by a predetermined setpoint of $300 \mathrm{Ah}$. Coatings were deposited on polished and ultrasonically cleaned WC-13 wt. \% Co substrates (ISO SNUN120408, $1.2 \times 1.2 \times 0.5 \mathrm{~cm}^{3}$ ) mounted on a drum fixture rotating with a speed of $3 \mathrm{rpm}$ as shown in Fig. 1(b). Seven substrates were mounted such that they covered an angular range of $0^{\circ}$ to $49^{\circ}$ from the surface normal of the cathode. Prior to the deposition of coatings, the substrates were etched with Ar ions.

The microstructures of virgin and arced material, as well as the coatings, were investigated using a LEO 1550 SEM equipped with an Oxford energy dispersive X-ray spectrometer (EDX). An acceleration voltage of $10 \mathrm{kV}$ at a working distance of $5 \mathrm{~mm}$ was used for imaging, while an acceleration voltage of $20 \mathrm{kV}$ at a working distance of $8.5 \mathrm{~mm}$ was used for elemental mapping and compositional analysis. A TiAlN sample of known composition was used to obtain calibrated EDX data, resulting in an accuracy of the compositional analysis of 5 at.\%. For viewing the microstructure of the converted layers by SEM, cross-sectional samples having dimensions of $1 \times 0.5 \times 0.5 \mathrm{~cm}^{3}$ were cut by a diamond blade. These samples were then embedded in a carbon based resin and polished by using the same regimen mentioned earlier.

A Zeiss 1540 EsB CrossBeam (FIB) was used to section the cathode surface features to reveal their microstructure. The macro-particle areal density of the coatings was measured by the box-counting method, i.e., by dividing SEM micrograph with an area of $2015 \mu \mathrm{m}^{2}$ into 60 boxes and then counting the macro-particles in each box. The number of macro-particles counted from 60 boxes was then divided by the area of micrograph to calculate the areal density of macro-particles. The lower limit on the radii of countable macro-particles was set at $50 \mathrm{~nm}$. Four micrographs from different locations along the diagonal of each coated substrate were used to gain a reliable average macro-particle areal density.

X-ray diffractometry of arced pieces, arced cathodes, and coatings was performed in $1^{\circ}$ grazing incidence geometry $^{16}$ using a PANalytical Empyrean diffractometer and $\mathrm{Cu}-\mathrm{K} \alpha$ radiation. Young's modulus of $429 \mathrm{GPa}$ and (a)

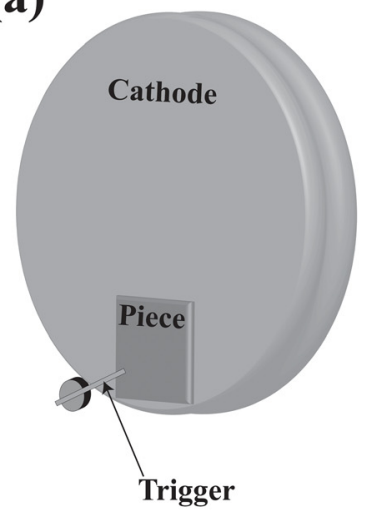

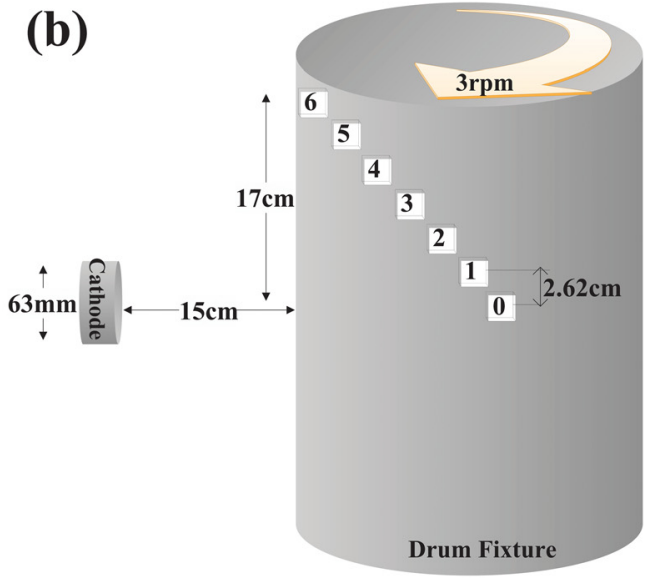

FIG. 1. (a) Schematic drawing of how a piece of $\mathrm{Ti}-50$ at.\% $\mathrm{Al}$ is glued to the surfaces of a dummy cathode. (b) Schematic drawing of the deposition geometry showing how the cathode, drum fixture, and the substrates were positioned (not to scale). 

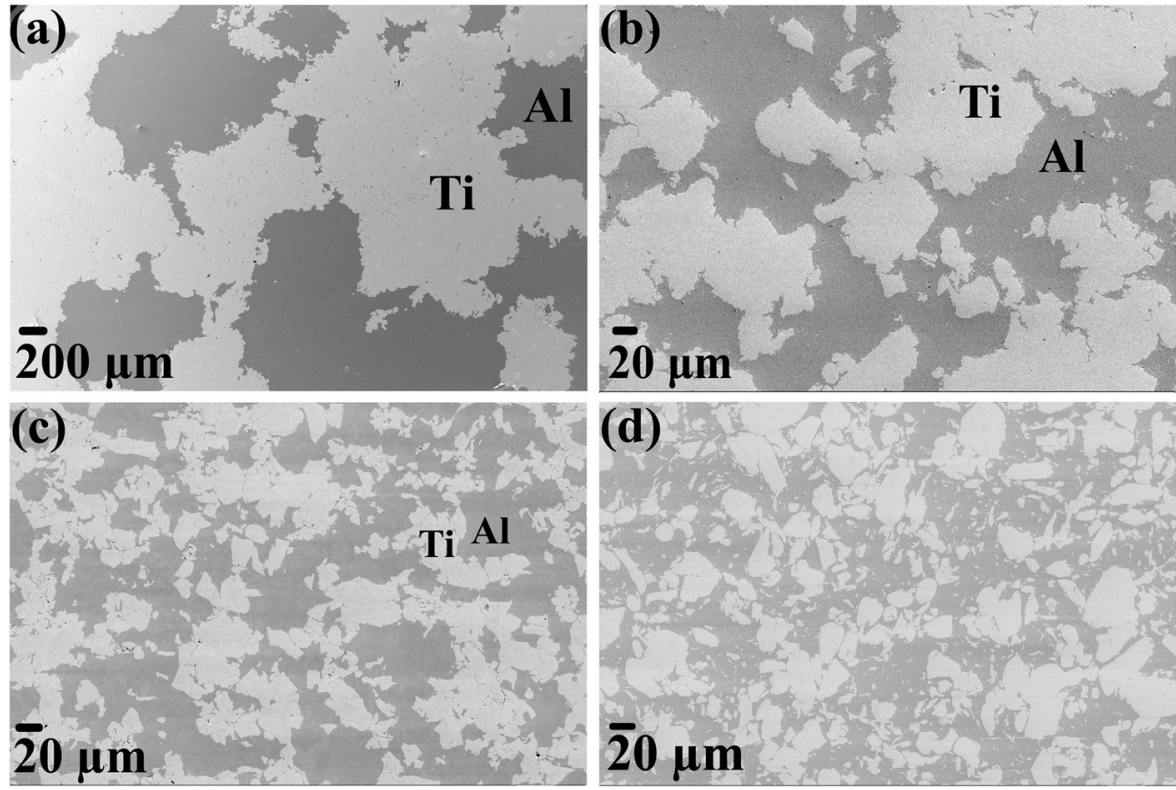

FIG. 2. SEM micrograph of virgin material (a) $1800 \mu \mathrm{m}$-grade, (b) $100 \mu \mathrm{m}$ grade, (c) $50 \mu \mathrm{m}$-grade, and (d) $10 \mu \mathrm{m}$ grade.
Poisson's ratio of 0.19 , as indicated by Mittemeijer et al. for $\mathrm{TiN}_{0.98},{ }^{17}$ were used to measure the stress of the coatings by using the $\sin ^{2} \psi$ method. ${ }^{16}$

The hardness of the coatings was evaluated by using a diamond Berkovich tip mounted on a load-controlled UMIS nanoindenter. The area function of the tip was calibrated using a fused silica reference sample. The hardness measurements were obtained from load-displacement curves by employing the method developed by Oliver and Phar. ${ }^{18}$ The hardness values reported were averaged from 40 indents at $25 \mathrm{mN}$ load with a maximum achieved penetration depth of $0.18 \mu \mathrm{m}$ on tapered (tapering angle $\left.5^{\circ}\right)^{19}$ and polished cross section of the coatings. The load of $25 \mathrm{mN}$ and taper polishing were used to mitigate the influences from the substrate and surface roughness on the recorded hardness.

\section{RESULTS}

Figure 2 shows SEM micrographs of polished virgin materials prepared from four grades. The grain size evaluation by the tangent rule performed on theses micrographs is in agreement with the result of the sieve analysis, suggesting limited or no grain growth during manufacturing. Figure 3 shows the x-ray diffractograms of polished virgin materials of all the four grades, showing that the virgin material of all four grades has a duplex structure of two phases: $\mathrm{Al}$ and Ti.

The traces of the arc on polished pieces of four different grades are shown in Fig. 4. In general, Al grains suffer more erosion than Ti grains, and the largest craters tend to appear at the shared peripheries of $\mathrm{Ti}$ and $\mathrm{Al}$ grains. The higher erosion rate of $\mathrm{Al}$ is expected since $\mathrm{Al}$ compared to $\mathrm{Ti}$ has a lower work function as well as cohesive energy. The reported work functions of $\mathrm{Ti}$ and $\mathrm{Al}$ ranges from 4.33 to $4.53 \mathrm{eV}$ (Refs. 1, 20, and 21) and 4.08 to $4.28 \mathrm{eV},,^{1,20,22}$ respectively. In the case of $\mathrm{Ti}-\mathrm{Si},{ }^{9} \mathrm{Zhu}$ et al. has shown that the phase with a low work function experiences a higher frequency of cathode spot events. The reported cohesive energies of $\mathrm{Ti}$ and $\mathrm{Al}$ are $4.86 \mathrm{eV} /$ atom (Ref. 23) and $3.34 \mathrm{eV} /$ atom, ${ }^{23}$ respectively. It has been established that, in general, cohesive energies of metals have an inverse relationship with the ion erosion rate. ${ }^{24}$

On the $1800 \mu \mathrm{m}$-grade, the largest crater appears on an Al grain and in close proximity of a Ti grain, and the diameter of this crater is around $850 \mu \mathrm{m}$, while the largest crater on a Ti grain is around $43 \mu \mathrm{m}$. An additional feature appears on this grade in the form of macro-bubbles (solidified bubbles) of $\mathrm{Al}$ located at the interface between the $\mathrm{Ti}$ and $\mathrm{Al}$ grains, as shown by the overlaid EDX elemental map in Fig. 5(a). Figure 5(b) shows the FIB excavated cross-section of the macro-bubble, confirming that these features are hollow.

For the $100 \mu \mathrm{m}$-grade, the recorded diameter of the largest craters on $\mathrm{Al}$ and $\mathrm{Ti}$ grains are approximately 18 and $2 \mu \mathrm{m}$, respectively. For the $50 \mu \mathrm{m}$-grade, the channels of $\mathrm{Al}$ sandwiched between Ti grains suffer higher erosion, the craters left at this channel site encompass the $\mathrm{Al}$ channel as well as the edges of the Ti grains. The largest crater of such kind has an approximate diameter of $27 \mu \mathrm{m}$, while the largest crater left on the $\mathrm{Al}$ and $\mathrm{Ti}$ grains have diameters of around $5 \mu \mathrm{m}$ and $2.5 \mu \mathrm{m}$, respectively.

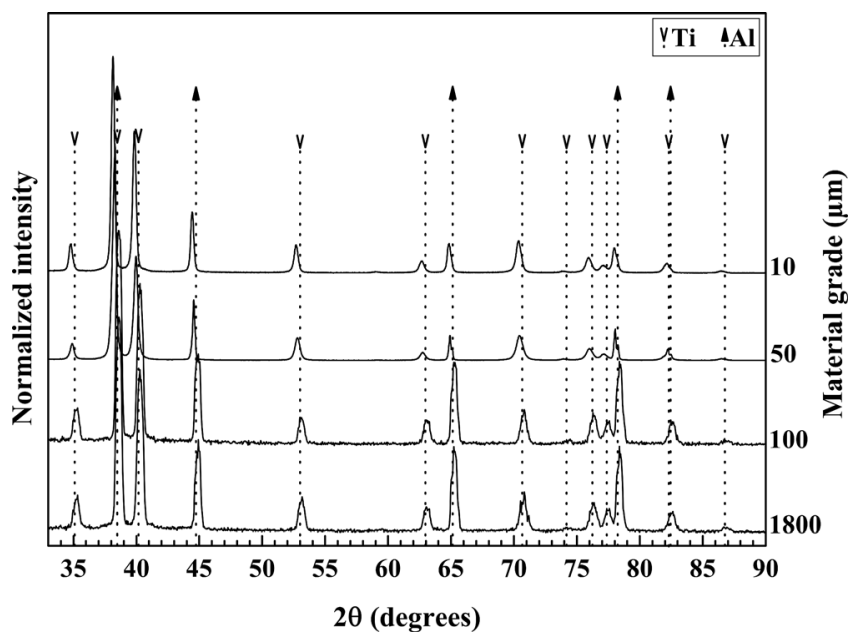

FIG. 3. X-ray diffractograms of all four grades of virgin material. 

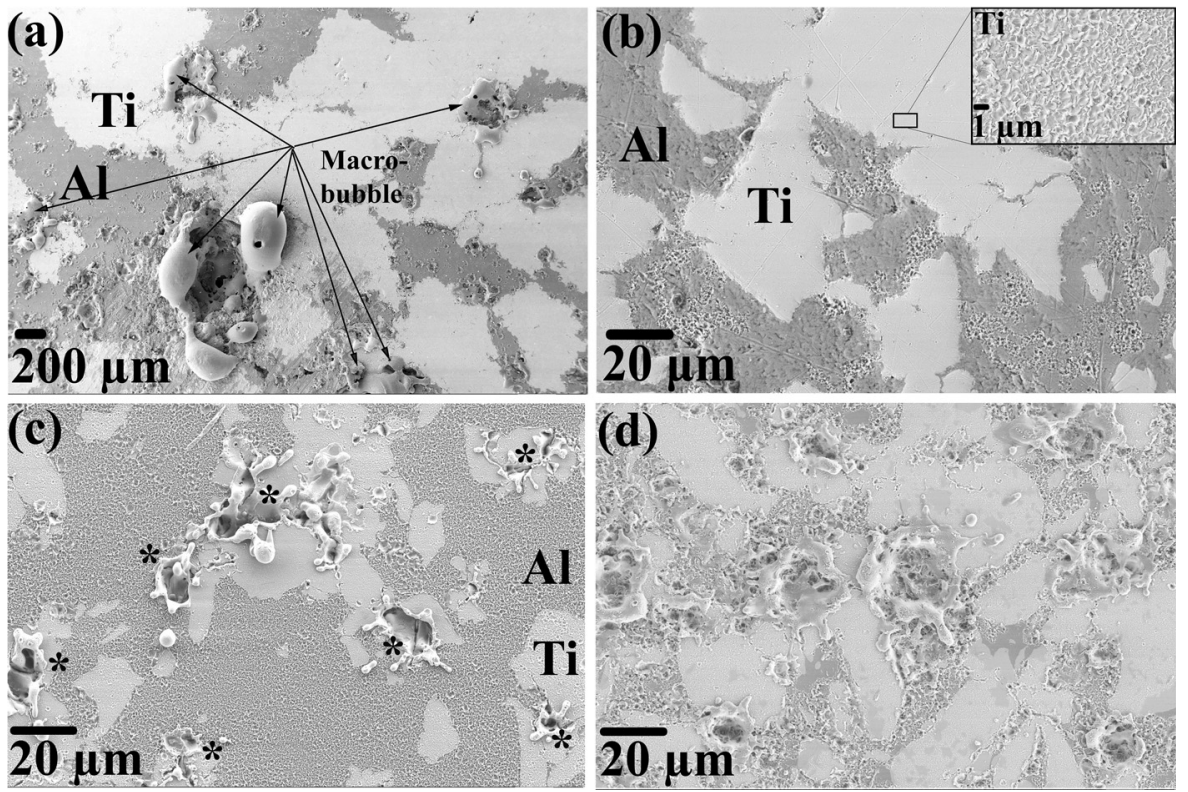

FIG. 4. SEM micrograph showing arc traces from a single trigger event on (a) polished $1800 \mu \mathrm{m}$-grade, (b) polished $100 \mu \mathrm{m}$-grade with an inset showing a magnified micrograph of Ti grain, (c) polished $50 \mu \mathrm{m}$-grade $(*$ denote the regions of arced $\mathrm{Al}$ sandwiched between $\mathrm{Ti}$ grains), and (d) polished $10 \mu \mathrm{m}$-grade.
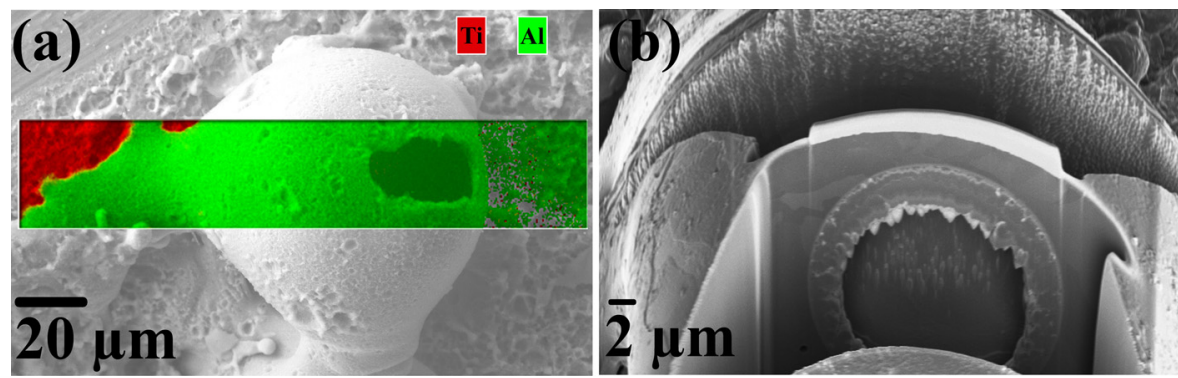

FIG. 5. (a) Scanning electron micrograph of macro-bubble with an EDX elemental map. (b) The excavation of macro-bubble achieved by Fib.

The erosion on the $10 \mu \mathrm{m}$-grade appears to be more pronounced compared to both the 100 and $50 \mu \mathrm{m}$-grades. The largest observable crater on the $10 \mu \mathrm{m}$-grade has an approximate diameter of $35 \mu \mathrm{m}$. For the $10 \mu \mathrm{m}$-grade, the virgin material [see Fig. 2(d)] consists of Ti grains with a diameter smaller than $5 \mu \mathrm{m}$ dispersed in the Al matrix. There appear to be abundant craters of diameters greater than $5 \mu \mathrm{m}$. This widespread dispersion of small $\mathrm{Ti}$ grains and abundance of craters larger than Ti grains makes it impossible to ascertain the diameter of largest craters on the $\mathrm{Ti}$ and $\mathrm{Al}$ grains.

The phase compositions of all the pieces after being arced with a single trigger event are shown in the $\mathrm{x}$-ray diffractrograms in Fig. 6. These diffractograms show that during the initial stage of arcing the $1800 \mu \mathrm{m}$-grade retains its virgin composition of $\mathrm{Ti}$ and $\mathrm{Al}$, the $100 \mu \mathrm{m}$-grade also shows the existence of just virgin phases, the $50 \mu \mathrm{m}$-grade shows the additional trace of $\zeta\left(\mathrm{Al}_{5} \mathrm{Ti}_{2}\right)$, and the $10 \mu \mathrm{m}$-grade additionally contains the intermetallic phase $\eta\left(\mathrm{Al}_{2} \mathrm{Ti}\right)$. Although the ambient gas during the single trigger event was $\mathrm{N}_{2}$, no $\mathrm{N}$-containing compounds were detected.

The optical image in Figs. 7(a)-7(d) shows the virgin and worn cathodes of all the four grades. The roughness of arced cathodes can be seen to decrease from the $1800 \mu \mathrm{m}$ grade to $50 \mu \mathrm{m}$-grade and then increase for the $10 \mu \mathrm{m}$-grade. SEM micrographs of the topography of the converted layers are shown in Figs. 7(i)-7(iv). The converted layer on the $1800 \mu \mathrm{m}$-grade hosts craters with diameters ranging from sub-micron to $3100 \mu \mathrm{m}$. This converted layer is enriched with craters of $2000 \mu \mathrm{m}$ diameter. The crater diameters on the converted layer of $100 \mu \mathrm{m}$-grade range from sub-micron to $62 \mu \mathrm{m}$. The converted layer on the $50 \mu \mathrm{m}$-grade hosts craters as well as hole-like features. The diameters of the craters range from sub-micron to $70 \mu \mathrm{m}$. The average diameter of the hole-like features in the converted layer of the $50 \mu \mathrm{m}$ grade is $25 \mu \mathrm{m}$, and these hole-like features occasionally have sub-holes. The diameters of the craters on the converted layer of the $10 \mu \mathrm{m}$-grade range from sub-micron to $22 \mu \mathrm{m}$ and the frequently occurring hole-like features are larger

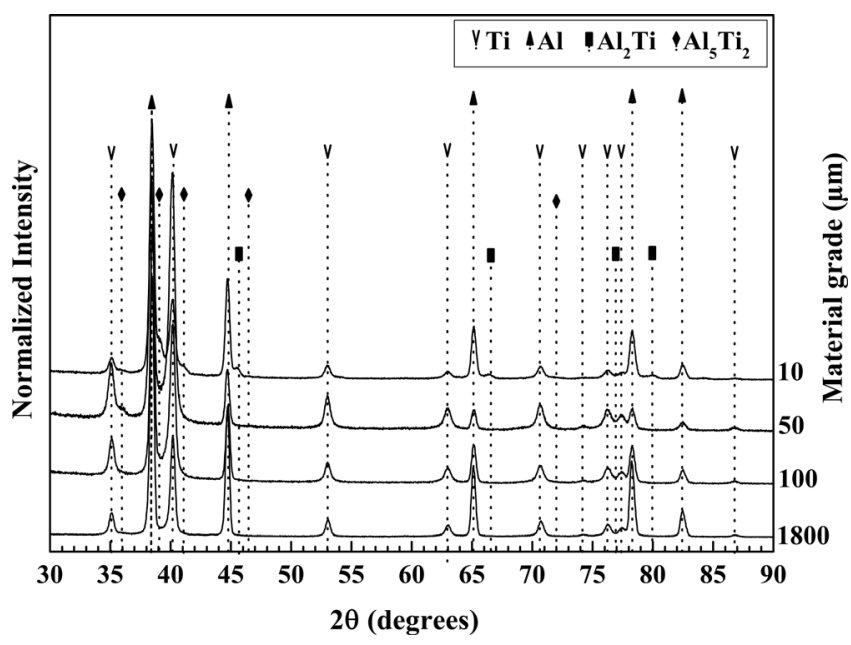

FIG. 6. X-ray diffractograms of all four grades after a single trigger event. 

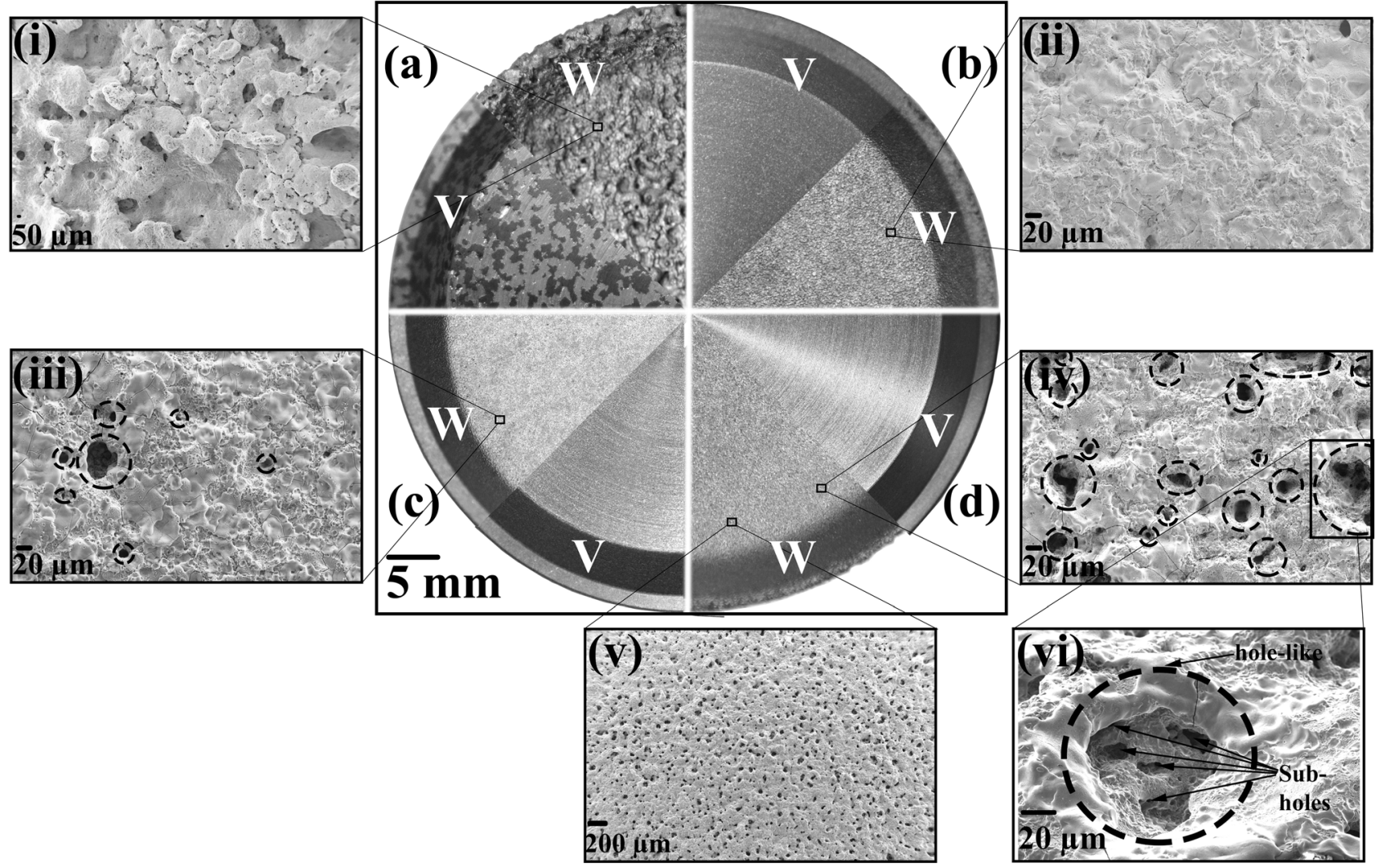

FIG. 7. (a)-(d) Images of all four grades of virgin (V) as well as worn (W) cathodes; (i)-(iv) are SEM micrographs showing the topography of all four grades of cathodes, the encircled regions in (iii) and (iv) host hole-like features; (v) represent the topography of $10 \mu \mathrm{m}$-grade cathode at low magnification indicating the extent of population density of hole-like features while (vi) the higher magnification of hole-like feature on $10 \mu \mathrm{m}$-grade cathode taken by tilting the stage at $45^{\circ}$; this shows that multiple sub-holes reside in a hole-like feature.

with an average diameter of $35 \mu \mathrm{m}$ and often contain multiple sub-holes, as shown in Fig. 7(vi).

The phase composition of the converted layers is shown by the x-ray diffractograms in Fig. 8. From the diffractograms, it can be seen that the converted layers on all the four grades of cathodes contain cubic(c)-TiAlN and the intermetallic phases $\zeta\left(\mathrm{Al}_{5} \mathrm{Ti}_{2}\right), \varepsilon\left(\mathrm{Al}_{3} \mathrm{Ti}\right)$, and $\eta\left(\mathrm{Al}_{2} \mathrm{Ti}\right)$. The converted layers of the $1800 \mu \mathrm{m}$-grade and $100 \mu \mathrm{m}$-grade also contain the virgin $\mathrm{Ti}$ and $\mathrm{Al}$ phases. A reduction in grain size

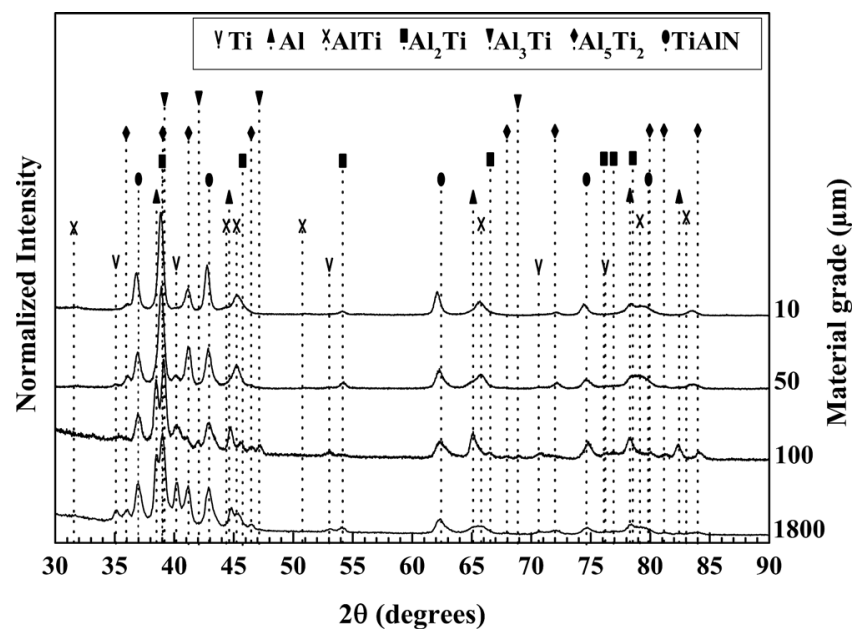

FIG. 8. X-ray diffractrograms showing the phase analysis of the converted layers on all four grades of cathodes. to $50 \mu \mathrm{m}$ results in the formation of the $\gamma$ (AlTi) phase while the Al phase disappears from the converted layer. Further reduction in grain size to $10 \mu \mathrm{m}$ enhances the intermixing of $\mathrm{Al}$ and $\mathrm{Ti}$ and now also the Ti phase disappears while the $\gamma$ (AlTi) phase appears in the converted layer. This trend suggests that a reduction in grain size of the cathode material promotes the mixing of $\mathrm{Ti}$ and $\mathrm{Al}$ to form the $\gamma$ phase.

Cross-sections of the converted layer on the four grades are shown in Fig. 9. The thickness of the converted layers are $14-50 \mu \mathrm{m}, 2-20 \mu \mathrm{m}, 6-40 \mu \mathrm{m}$, and $16-50 \mu \mathrm{m}$ on $1800 \mu \mathrm{m}-$ grade, $100 \mu \mathrm{m}$-grade, $50 \mu \mathrm{m}$-grade, and $10 \mu \mathrm{m}$-grade, respectively. No difference in the erosion of $\mathrm{Ti}$ and $\mathrm{Al}$ grains could be distinguished for the $100 \mu \mathrm{m}$-grade, while $\mathrm{Al}$ grains suffer higher erosion for all the other cathodes. Figs. 9(c) and 9(d) show cross-sections of the previously mentioned sub-holes. These sub-holes are present at the interface between the converted layer and the virgin microstructure. In fact, it appears as if the holes are located where there used to be Al-grains in the virgin microstructure. The summary of above mentioned results is tabulated in Table I.

Figure 10 shows plan view micrographs of the coatings grown by the four different cathode grades. These coatings are grown on WC- $13 \mathrm{wt}$ \% Co substrates placed at position 0 , as indicated by the deposition geometry shown in Fig. 1(b). The coating grown by the $1800 \mu \mathrm{m}$-grade appears to be laden with spherical as well as flattened macro-particles. The coatings grown by the $100 \mu \mathrm{m}$-grade, as well as $50 \mu \mathrm{m}$-grade, have only spherical macro-particles, and the coating grown by 


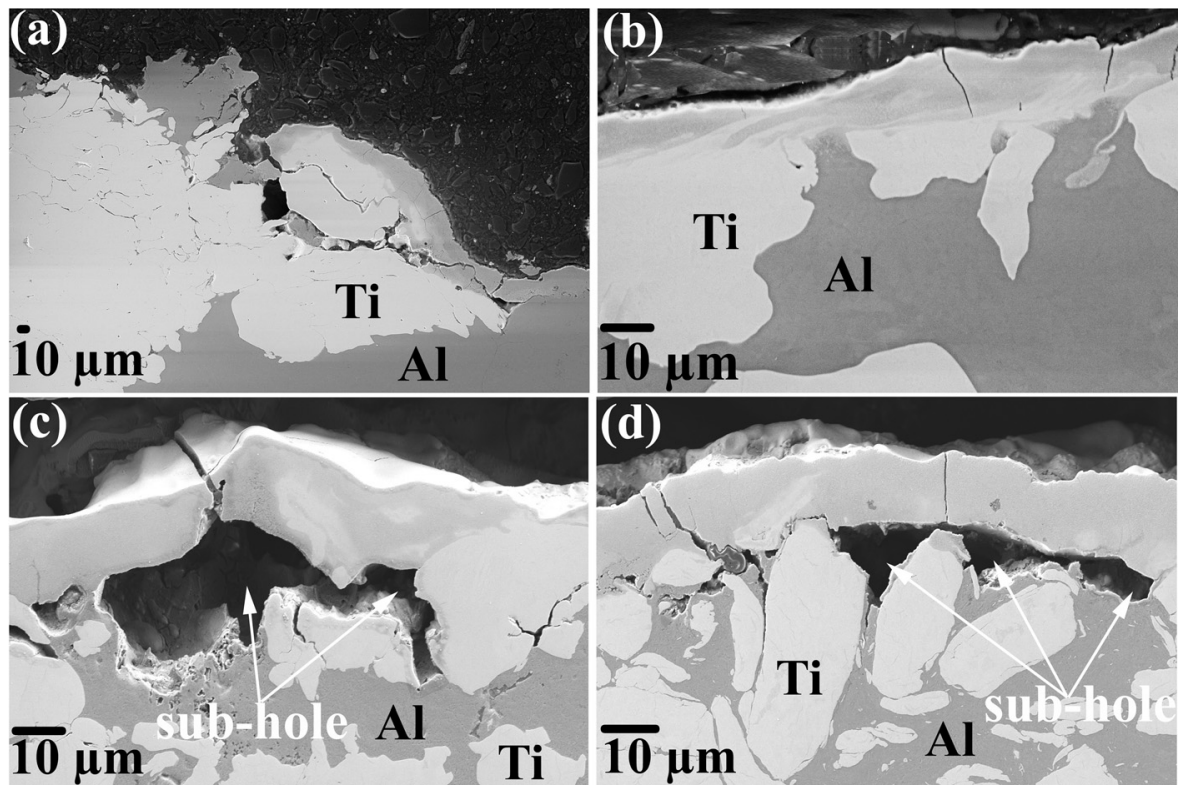

FIG. 9. SEM micrograph of the cross section of converted layers of (a) $1800 \mu \mathrm{m}$-grade, (b) $100 \mu \mathrm{m}$-grade, (c) $50 \mu \mathrm{m}$-grade, and (d) $10 \mu \mathrm{m}$-grade; the cross-section of sub-holes mentioned in Figs. 8(c) and 8(d) c.

TABLE I. Summarized attributes of all four grades on arcing.

\begin{tabular}{|c|c|c|c|c|}
\hline Attribute & $1800 \mu \mathrm{m}$-grade & $100 \mu \mathrm{m}$-grade & $50 \mu \mathrm{m}$-grade & $10 \mu \mathrm{m}$-grade \\
\hline Phases present (single trigger) & $\mathrm{Ti}, \mathrm{Al}$ & $\mathrm{Ti}, \mathrm{Al}$ & $\mathrm{Ti}, \mathrm{Al}, \zeta$ & $\mathrm{Ti}, \mathrm{Al}, \zeta, \eta$ \\
\hline $\begin{array}{l}\text { Largest crater diameter on } \mathrm{Ti} \\
\text { and } \mathrm{Al} \text { grains }\end{array}$ & $\mathrm{Al} \sim 850 \mu \mathrm{m}, \mathrm{Ti} \sim 43 \mu \mathrm{m}$ & $\mathrm{Al} \sim 18 \mu \mathrm{m}, \mathrm{Ti} \sim 1.7 \mu \mathrm{m}$ & $\mathrm{Al} \sim 5 \mu \mathrm{m}, \mathrm{Ti} \sim 2.5 \mu \mathrm{m}$ & Largest crater $\sim 35 \mu \mathrm{m}$ \\
\hline Special features & Al macro-bubbles & $\ldots$ & $\begin{array}{c}\text { Arced Al sandwiched between } \\
\text { Ti grains }\end{array}$ & Pronounced erosion \\
\hline Phases present (steady state) & $\mathrm{Ti}, \mathrm{Al}, \mathrm{c}-\mathrm{TiAlN}, \zeta, \eta, \varepsilon$ & $\mathrm{Ti}, \mathrm{Al}, \mathrm{c}-\mathrm{TiAlN}, \zeta, \eta, \varepsilon$ & Ti, c-TiAlN, $\zeta, \eta, \varepsilon, \gamma$ & c-TiAlN, $\zeta, \eta, \varepsilon, \gamma$ \\
\hline Observable crater diameter & Sub-micron-3100 $\mu \mathrm{m}$ & Sub-micron-62 $\mu \mathrm{m}$ & Sub-micron-70 $\mu \mathrm{m}$ & Sub-micron-22 $\mu \mathrm{m}$ \\
\hline Converted layer thickness & $14-50 \mu \mathrm{m}$ & $2-20 \mu \mathrm{m}$ & $6-40 \mu \mathrm{m}$ & $16-50 \mu \mathrm{m}$ \\
\hline Special features & Large and deep craters & $\ldots$ & $\begin{array}{l}\text { Hole-like features (sparse) } \\
\text { with sub-holes }\end{array}$ & $\begin{array}{l}\text { Hole-like features (frequent) } \\
\text { with sub-holes }\end{array}$ \\
\hline
\end{tabular}

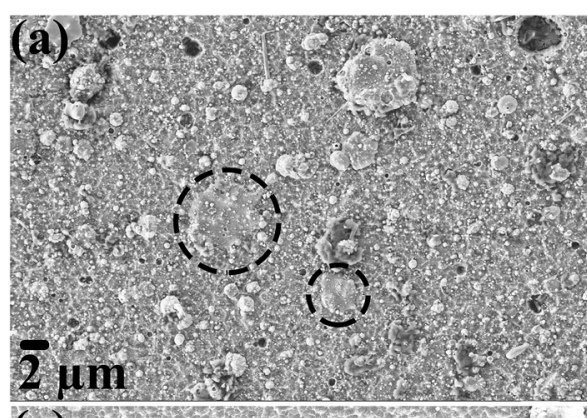

(c)

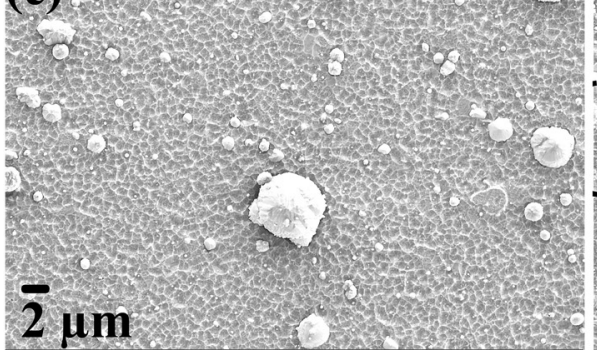

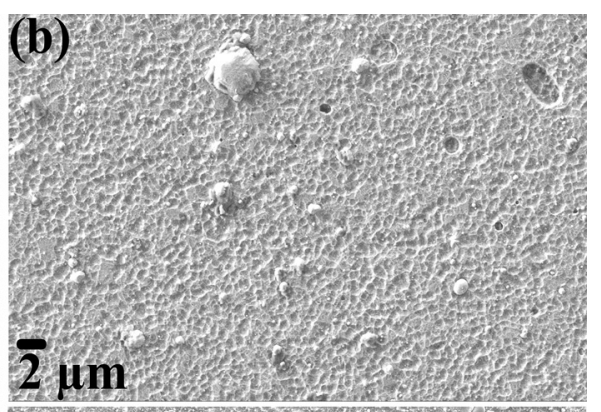

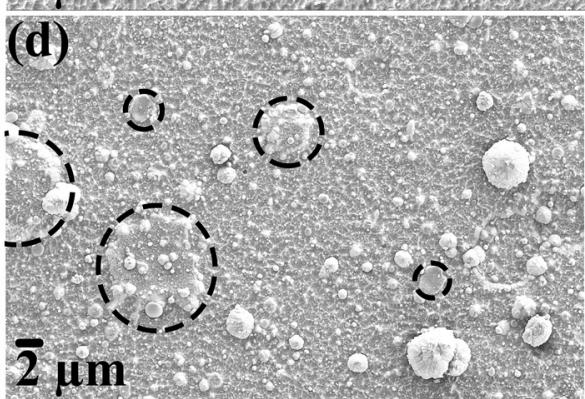

FIG. 10. SEM micrograph of the TiAl-N coatings (position 0 as shown in Fig. 2) deposited from (a) $1800 \mu \mathrm{m}$ grade, (b) $100 \mu \mathrm{m}$-grade, (c) $50 \mu \mathrm{m}$ grade and (d) $10 \mu \mathrm{m}$-grade; encircled regions in (a) and (d) denote flattened macro-particles. the $100 \mu \mathrm{m}$-grade shows the fewest macro-particles among the four coatings. The coating grown by the $10 \mu \mathrm{m}$-grade have both flat and sphere shaped macro-particles [Fig. 12(d)]. The abundance of macro-particles on the coating grown by the 10 and $1800 \mu \mathrm{m}$-grades makes the hardness measurements of these coatings unreliable. The coatings grown from the 50 and $100 \mu \mathrm{m}$-grades show a hardness of around $30 \mathrm{GPa}$. 
The x-ray diffractograms shown in Fig. 11 indicate that the coatings are comprised of $c-\mathrm{Ti}_{1-\mathrm{x}} \mathrm{Al}_{\mathrm{x}} \mathrm{N}$. Their residual stress is in the range of -2.5 to $-3.1 \mathrm{GPa}$. Examination of the positions of the diffraction peaks illustrates shifts towards higher angles for the coatings grown from $1800 \mu \mathrm{m}$-grade and $10 \mu \mathrm{m}$-grade compared to those grown from the other grades. These shifts are larger than what is caused by the residual stress, and instead, they are the consequence of differences in chemical composition, i.e., coatings grown by the $1800 \mu \mathrm{m}$ grade and $10 \mu \mathrm{m}$-grades have a higher $\mathrm{Al}$ content than the other two coatings. The appearance of flattened macroparticles on these coatings suggests these macro-particles to have still been in a liquid state when impacting on the growing coating, and then solidified in a flat geometry.

The variation of the coating thickness and areal density of the macro-particles are plotted as a function of angular spread in Figs. 12 and 13, respectively. It should be noted that the angle of the angular spread represents the positions where the surface normal of the substrate become antiparallel to the surface normal of the cathode during a revolution of the drum fixture [see Fig. 1(b)], i.e., the coating grown at position 0 is represented by $0^{\circ}$ angular spread even though it traverses an angular distance of $-30^{\circ}$ to $+30^{\circ}$ in front of the cathode during the deposition. Coating thickness decreases with increasing distance from the cathode for all cathode grades, which is a result of the expected angular distribution of the ion flux from an arc cathode source. ${ }^{25}$ However, the distinct differences between the cathode grades are seen. The coatings grown by the $10 \mu \mathrm{m}$-grade show the highest growth rate while the other 3 grades show similar and lower growth rate. The coatings grown from the $1800 \mu \mathrm{m}$-grade have the highest macro-particle areal density. The maximum macro-particle areal density for coatings grown by $1800 \mu \mathrm{m}$-grade, as well as coatings grown by the $10 \mu \mathrm{m}$-grade, occurs at an angular spread of $\sim 21^{\circ}$. For the coatings grown by the $50 \mu \mathrm{m}$-grade cathode, the maximum is shifted to $\sim 30^{\circ}$ and for the $100 \mu \mathrm{m}$-grade to $\sim 43^{\circ}$.

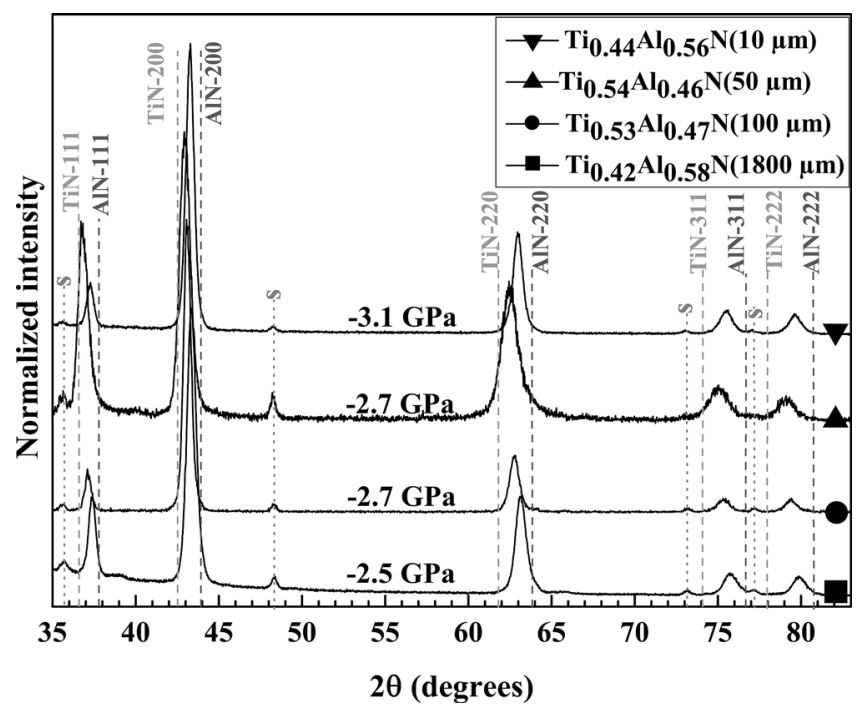

FIG. 11. XRD diffractrograms of the coatings shown in Fig. 10; the measured residual stresses in the coatings are also stated along with the chemical composition.

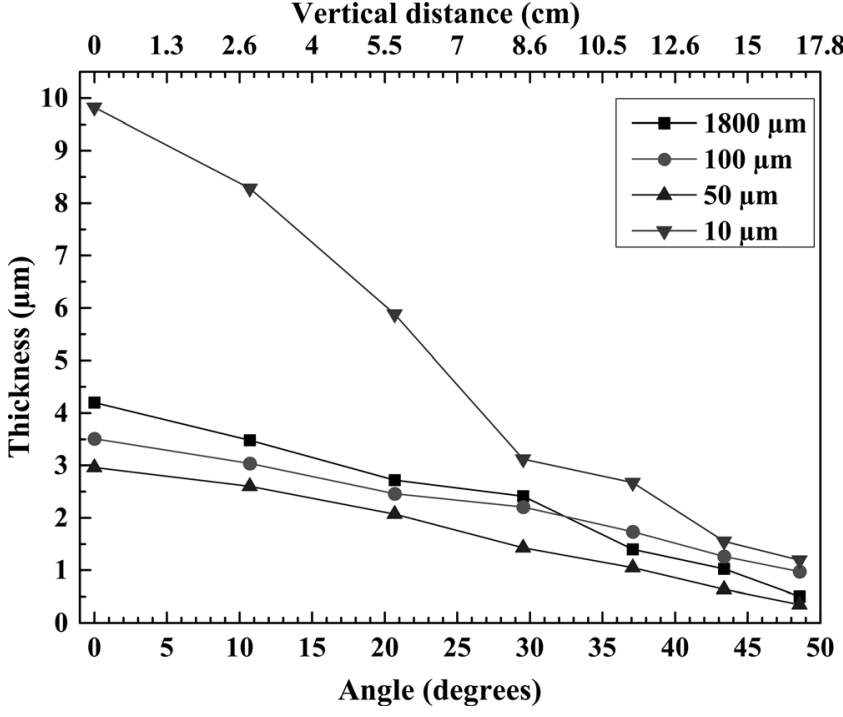

FIG. 12. Graphical representation of the variation of the thickness of the coatings, grown from all four grades of the cathodes, as a function of the angular distance of the substrates from the surface normal of the cathode; the corresponding vertical distance of the substrates on the drum fixture is also shown.

\section{DISCUSSION}

\section{A. Formation and evolution of the converted layers}

The composite manufactured material of all the four grades of Ti-50 at.\% $\mathrm{Al}$ has a matrix of pure $\mathrm{Al}$ with Ti particles. Al suffers higher erosion compared to Ti during the initial stage of the formation of the converted layer, irrespective of the grain size. Several factors contribute to the higher erosion of $\mathrm{Al}$, including the inverse relation between the ion erosion rate and cohesive energy of metals. ${ }^{24}$ The cohesive energy of $\mathrm{Al}$ is approximately $1.5 \mathrm{eV} /$ atom lower than Ti. A second factor favoring higher erosion of $\mathrm{Al}$ over $\mathrm{Ti}$ grains is

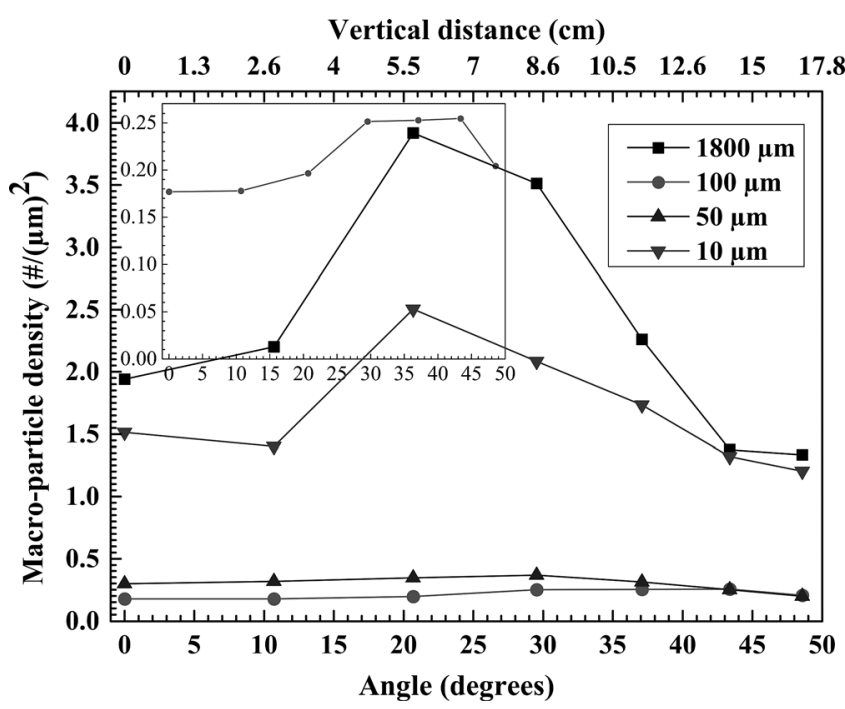

FIG. 13. Graphical representation of the macro-particle areal density of the coatings deposited from all four grades of the cathodes as a function of angular distance of the substrates from the surface normal of the cathode; the corresponding vertical distance of the substrates on the drum fixture is also shown; the inset shows the re-scaled version of the macro-particle areal density of the coatings deposited by $100 \mu \mathrm{m}$-grade. 
the difference of $0.4 \mathrm{eV}$ in work function. The cathodic arc evaporation process is perpetual in such a way that it keeps the supply of electrons to the anode from the cathode by continually igniting new cathode spots at locations on the cathode surface that offer the least resistance to electron emission. Since the work function is lower for $\mathrm{Al}$ than $\mathrm{Ti}, \mathrm{Al}$ grains are expected to host more cathode spots, which contribute to the abundant erosion of Al. A third factor yielding a more pronounced erosion of $\mathrm{Al}$ than $\mathrm{Ti}$ is related to the fact that metals with low melting temperatures emanate more macro-particles. ${ }^{26}$ The reported melting temperatures of $\mathrm{Al}$ and $\mathrm{Ti}$ are $660^{\circ} \mathrm{C}$ (Ref. 27) and $1670{ }^{\circ} \mathrm{C},{ }^{28}$ respectively. The temperature of the cathode surface close to a cathode spot is reported to be in the range of $1500-4500^{\circ} \mathrm{C}$ depending on the cathode material. ${ }^{29-31}$ This temperature range is more than enough to melt the surface of both $\mathrm{Ti}$ and $\mathrm{Al}$ grains and the excess heat is dissipated by increasing the volume of the molten pool on the surface. Since $\mathrm{Al}$ has a lower melting temperature than $\mathrm{Ti}$, the molten pools on $\mathrm{Al}$ grains are expected to be larger than those on $\mathrm{Ti}$ grains. Macro-particles are then ejected from the molten pools as droplets by the high plasma pressure, and droplets are formed more easily from large superheated pools and they tend to be larger than those from small pools, causing a higher erosion rate of $\mathrm{Al}$.

The eruption of $\mathrm{Al}$ grains to form macro-bubbles appearing at the interface between $\mathrm{Ti}$ and $\mathrm{Al}$ grains occurs only on the $1800 \mu \mathrm{m}$-grade. It resembles the phenomenon of a cathode spot anchoring on the liquid metal when an immersed solid metal is present. ${ }^{32-35} \mathrm{As}$ an $\mathrm{Al}$ grain adjacent to a Ti grain melts, the edge of the Ti grain can effectively be seen as being immersed in liquid Al. It anchors the arc at this position and brings the liquid $\mathrm{Al}$ to boil. The boiling $\mathrm{Al}$ forms bubbles that solidify when coming in contact with the cooler parts of the cathode surface outside the liquid pool. The diameter of the craters that contain macro-bubbles is more than $200 \mu \mathrm{m}$. In order for the cathode spot to anchor, liquid $\mathrm{Al}$ must wet the solid metal (Ti) to a certain dimension, which is only fulfilled for the $1800 \mu \mathrm{m}$-grade. The grain size is too small for arc anchoring in the other three grades, which explains why macro-bubbles are not observed for these grades.

A crude calculation, when approximating the grains as spheres, gives the interface area in a box of $1 \mathrm{~cm}^{3}$ to be 17 , 300,600 , and $3000 \mathrm{~cm}^{2}$ for $1800,100,50,10 \mu \mathrm{m}$ grains, respectively. A material with such a large interface area as the $10 \mu \mathrm{m}$-grade is expected to suffer from pronounced phonon scattering, which makes it a poorer thermal conductor compared to the grades of larger grain sizes. Large interfacial areas and poor thermal conductivities are instrumental for the formation of intermetallic phases seen for the 50 and $10 \mu \mathrm{m}$-grade during the initial stage of evolution of converted layers. The interfaces between $\mathrm{Al}$ and $\mathrm{Ti}$ grains are the expected sites for the formation of intermetallic phases. Since there are fewer interfaces in the 1800 and $100 \mu \mathrm{m}$ grade as compared to the other grades, there is a low probability for a cathode spot at such an interface and even if the cathode spot finds an interface, the good thermal conductivity of these grades warrants rapid quenching of the melt.
Such rapid quenching does not provide the time needed to form intermetallic phases.

On the other hand, the large interface area and poor thermal conductivities in the cases of 50 and $10 \mu \mathrm{m}$-grades generate more favorable conditions for the formation of intermetallic phases. The intermetallic phases in the Ti-Al phase diagram, according to their ascending free energy of formation, are $\eta, \zeta, \varepsilon$, and $\gamma \cdot{ }^{36}$ Under thermodynamic equilibrium the formation of the $\zeta$ phase requires the presence of the $\gamma$ phase. ${ }^{36,37}$ However, the arcing phenomenon is transient in nature, ${ }^{38}$ which is in contrast to the thermodynamic equilibrium condition. During such conditions, the kinetics may dominate thermodynamics and lead the system to form the intermetallic $\zeta$ phase. The $\eta$ phase is known to exist in equilibrium with the liquid phase in the Ti-Al phase diagram. ${ }^{36}$ Since the surface of the $10 \mu \mathrm{m}$-grade is expected to retain heat for a longer period of time than the $50 \mu \mathrm{m}$-grade, one may expect that thermodynamic equilibrium is reached at localized places to form the $\eta$ phase along with $\zeta$.

\section{B. Steady-state condition of the converted layers and the effect on coatings}

The multiple instances of the cathode spot even out the macro-bubbles observed during the initial stage of the converted layer on the $1800 \mu \mathrm{m}$-grade [see Fig. 7(i)]. The presence of both $\mathrm{Al}$ and $\mathrm{Ti}$ phases in the converted layers on $100 \mu \mathrm{m}$-grade and $1800 \mu \mathrm{m}$-grade (see Fig. 8) indicates that during the steady-state operation of the cathodes they keep their entity as separate phases in the converted layers. In the converted layer of the $1800 \mu \mathrm{m}$-grade, the $\mathrm{Al}$ phase has the lowest work function and cohesive energy among the detected phases, and is hence expected to host more cathode spot events and a higher erosion rate compared to $\mathrm{Ti}$ and other intermetallic phases. This biased erosion of $\mathrm{Al}$ grains creates surface asperities giving rise to a rough appearance. The direct consequence of this phenomenon is the presence of flattened macro-particles on the coatings grown by $1800 \mu \mathrm{m}$-grade. Since Al has a lower melting temperature than $\mathrm{Ti}$, it is expected that these flattened macro-particles are $\mathrm{Al}$ rich and they require a lower temperature or a longer time to solidify; as a result, these macro-particles reach the substrate in the liquid state. However, the $\mathrm{Ti}$ rich macroparticles reach the substrate in a solidified state, resulting in the formation of macro-particles of spherical geometry. The relatively thick $(50 \mu \mathrm{m})$ converted layer on the surface of $1800 \mu \mathrm{m}$-grade is a result of preferential erosion and the anchoring of the cathode spot. This cathode spot behavior dissipates more heat locally, which extends the converted layer to a greater depth compared to the other grades. The preferential erosion of $\mathrm{Al}$ ( $\mathrm{Al}$ ion erosion and $\mathrm{Al}$-rich macroparticles) also explains high $\mathrm{Al}$-content $\left(\mathrm{Ti}_{0.42} \mathrm{Al}_{0.58} \mathrm{~N}\right)$ in the coatings grown from the $1800 \mu \mathrm{m}$-grade.

The steady-state condition of the converted layer for the $100 \mu \mathrm{m}$-grade is reached in a similar manner as that of the converted layer for the $1800 \mu \mathrm{m}$-grade. However, the grain size, in this case, is substantially smaller, which means that the asperities, originating from the preferential erosion of $\mathrm{Al}$, render the adjacent phases having higher work functions, to 
form sharp micro-protrusions. The micro-protrusions are known to have a local field enhancement effect during the cathodic arc process, ${ }^{39}$ which in turn decreases the effective work function for these micro-protrusions. As a consequence, these micro-protrusions are favorable cathode spot sites that act to reduce the surface roughness causing a more uniform erosion of the converted layer. Compared to coatings deposited by the other grades, this uniform erosion process promotes the stoichiometric coatings and generates the lowest macro-particle density.

The lack of $\mathrm{Al}$, presence of a $\gamma$ phase, and the appearance of sub-holes (porosity) at the steady state condition of the converted layers for the 10 and $50 \mu \mathrm{m}$-grade suggest that the cohesion of factors like large interfacial area, poor thermal conductivity, and heat due to arcing provide a prosperous environment for initiation of a self-sustaining reaction underneath the converted layers along the $\mathrm{Al}$ channels sandwiched between the Ti grains. As the heat from the cathode is removed by a water cooled $\mathrm{Cu}$ plate placed at the backside of the cathode, the surface region of the cathode is expected to be hotter than the bulk region, and is, thus, a preferential region for the self-sustaining reaction wave front to proceed, which explains why the Al channels parallel to the surface form sub-holes.

Compacts of $\mathrm{Ti}$ and $\mathrm{Al}$ particles are known to initiate a self-sustaining combustion reaction at an adiabatic temperature of $1300{ }^{\circ} \mathrm{C}$ that yields the $\gamma$ phase as the final product; ${ }^{40}$ this reaction proceeds by forming $\varepsilon$ phase in an exothermic reaction. The heat generated in this intermediate step further melts $\mathrm{Al}$, heats the compact and activates the diffusion needed to transform $\varepsilon$ to $\gamma^{40,41}$ Increasing the initial temperature of the Ti-Al compact ${ }^{40}$ and decreasing the grain size of the $\mathrm{Ti}^{40,42}$ result in a short initiation time for this selfsustaining reaction. The decrease in the Ti grain size also enhances the speed of the self-sustaining reaction wave front. ${ }^{40}$ At the completion of such self-sustaining reactions the compact is prone to have porosity chiefly due to factors such as Kirkendall porosity where the difference in diffusivity of $\mathrm{Al}$ and $\mathrm{Ti}$ forms the pores at the $\mathrm{Al}$ grain sites ${ }^{43}$ and the shrinkage porosity is caused by the $5.3 \%$ higher density of the $\gamma$ phase compared to the Ti-Al powder compact. ${ }^{44}$

The primary cause of the appearance of hole-like features on the converted layers of 50 and $10 \mu \mathrm{m}$-grade during the steady state [see Figs. 7(iii) and 7(iv)] lies in the work function of the metals that decreases linearly as their temperatures increase. ${ }^{45}$ When heat from the cathode spot initiates a self-sustaining reaction underneath the converted layer, the localized temperature of the constituents of the converted layer directly above the proceeding reaction front increases, causing their work functions to decrease. Such locations offer good conditions for bearing new cathode spots. The temperature is expected to be quite high due to the residual heat generated from the self-sustaining reaction, and the ignition of the cathode spot further increases the temperature of the region surrounding this site. As a consequence, this site melts rapidly, and a deep and wide molten pool is formed. Under plasma pressure, the liquid from this pool is forced out as macro-particles, and thus, deep and wide holelike features appear.
Besides offering localized places of low work function, the $\mathrm{Al}$ phase in the converted layers of the 100 and $1800 \mu \mathrm{m}$ grade also provide the pathways for heat conduction because of its high thermal conductivity, while the dearth of $\mathrm{Al}$ in the converted layers of the 10 and $50 \mu \mathrm{m}$-grades can be expected to yield a poor thermal conductivity. The density of macroparticles is directly proportional to the surface temperature of the cathode. ${ }^{46}$ The high macro-particle density of the coatings grown by $50 \mu \mathrm{m}$-grades compared to $100 \mu \mathrm{m}$-grade is related to the self-sustaining exothermic reaction, which consumes the $\mathrm{Al}$ phase. This consumption reduces the thermal conductivity and further increases the temperature of the converted layer on the $50 \mu \mathrm{m}$-grade. During the steady state arcing, the converted layer on the $10 \mu \mathrm{m}$-grade displays no Ti phase (see Fig. 8) and abundant hole-like features [see Fig. 7(v)], which suggests that for this even finer microstructure, the conditions for the self-sustaining reaction enabling the formation of $\gamma$ phase are fulfilled more frequently than for the $50 \mu \mathrm{m}$-grade. The high macro-particle density of the coatings grown by the $10 \mu \mathrm{m}$-grade (see Fig. 13) is similarly linked to the high temperature of the converted layer due to the dearth of the Al phase and a significantly higher frequency of the self-sustaining reaction.

The absence of the Al-phase in the converted layer also diminishes the difference in work function among the constituents $\left(\zeta, \varepsilon, \eta, \gamma\right.$, and Ti) to $0.1 \mathrm{eV} ;{ }^{47}$ this reduction in the disparity of the work function provides a nearly equal probability for the cathode spot events. It is also the reason why the arced $50 \mu \mathrm{m}$-grade appears smooth compared to other three grades [see Figs. 7(a)-7(d)].

The appearance of flattened macro-particles on the coatings grown by the $10 \mu \mathrm{m}$-grade [see Fig. 10(d)] is due to the fact that the hole-like features created by the interaction of self-sustaining reaction and the arc activity are filled with the molten metal pools. Since the liquefied Al channels are formed during the self-sustaining reaction, the molten metal pools in the hole-like features are expected to be rich in Al. This super-hot liquid under plasma pressure is jettisoned towards the substrate, where it strikes the substrate in the liquefied form and upon solidification forms flattened macroparticles. These flattened macro-particles enriched in $\mathrm{Al}$ are responsible for the high $\left(\mathrm{Ti}_{0.44} \mathrm{Al}_{0.56} \mathrm{~N}\right)$ Al-content of the coatings grown by the $10 \mu \mathrm{m}$-grade. The abundance of these flattened macro-particles in the coatings grown by the $10 \mu \mathrm{m}$-grade results in an apparently high growth rate (see Fig. 12).

The maximum of macro-particle density of the coatings grown by the 1800 and $10 \mu \mathrm{m}$-grades is shifted towards smaller angles from the normal surface of the cathode compared to other cathode grades (see Fig. 13). The plausible reason for this shift could be that these grades have deep asperities whose walls are quite steep compared to the other grades. The plasma pressure is expected to force the liquid out of such an asperity. The molten liquid held by the walls of the asperity is then guided out in approximately the same direction as the walls. This can be understood from the schema in Fig. 14, which shows how the molten metal under the plasma pressure is jettisoned from (a) shallow asperity as 


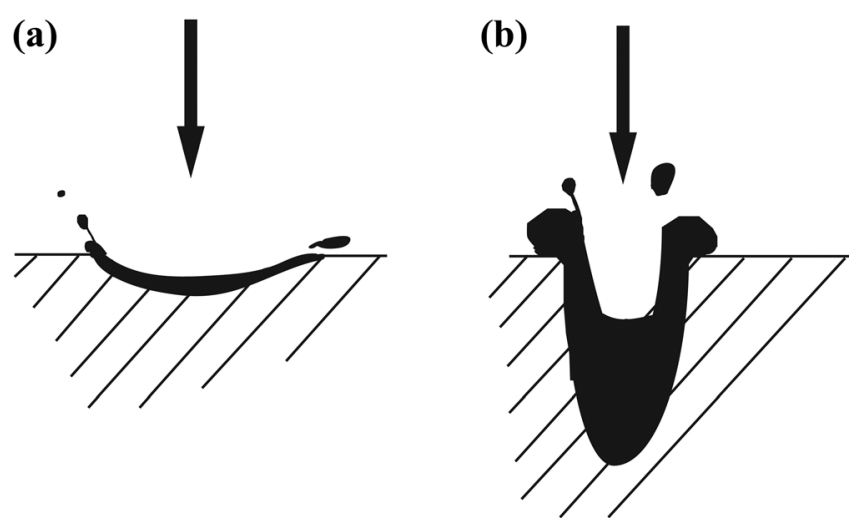

FIG. 14. Schema of the ejection mechanism of macro-particles from (a) a shallow crater, and (b) a deep and steep crater with the arrow representing the plasma pressure.

in the case of the 100 and $50 \mu \mathrm{m}$-grades, and (b) deep and steep asperity as in the case of the 1800 and $10 \mu \mathrm{m}$-grades.

\section{CONCLUSION}

In this article, we report on the evolution of the morphology and microstructure of Ti-50 at.\% Al powder metallurgical cathodes, as a function of their grain sizes (1800, 100, 50 and $10 \mu \mathrm{m}$ ), during the cathodic arc deposition of Ti-Al-N coatings. The primary factors that influence the evolution of the microstructure and morphology of the $1800 \mu \mathrm{m}$ grain sized material are the disparity of the work function among the parent phases, as well as the anchoring of the cathode spots. These two factors contribute to the high Al content in the deposited coatings. The reduction in grain size to $100 \mu \mathrm{m}$ enhances the intermixing of the parent phases, which mitigates the anchoring phenomenon and results in the coatings having equal content of $\mathrm{Ti}$ and $\mathrm{Al}$. Further reduction in the grain size creates favorable conditions for the initiation of the self-sustaining reaction to form the $\gamma$ phase. For the 10 and $50 \mu \mathrm{m}$ grain size cathodes the self-sustaining reaction is the dominant factor affecting the evolution of the morphology and microstructure of the cathodes during arcing. On the $10 \mu \mathrm{m}$ grain size cathode, self-sustaining reactions occur so frequently that the coatings become rich in $\mathrm{Al}$ and laden with macro-particles.

\section{ACKNOWLEDGMENTS}

The authors acknowledge the financial support from VINN Excellence Center in Research and Innovation on Functional Nanoscale Materials (FunMat) by the Swedish Governmental Agency for Innovation Systems.

${ }^{1}$ A. Anders, Cathodic Arcs, 1st ed. (Springer-Verlag, New York, 2008).

${ }^{2}$ L. Rogström, J. Ullbrand, J. Almer, L. Hultman, B. Jansson, and M. Odén, "Strain evolution during spinodal decomposition of TiAlN thin films," Thin Solid Films 520, 5542-5549 (2012).

${ }^{3}$ D. Rafaja, A. Poklad, V. Klemm, G. Schreiber, D. Heger, M. Šíma et al., "Some consequences of the partial crystallographic coherence between nanocrystalline domains in Ti-Al-N and Ti-Al-Si-N coatings," Thin Solid Films 514, 240-249 (2006).

${ }^{4}$ A. Knutsson, J. Ullbrand, L. Rogström, N. Norrby, L. J. S. Johnson, L. Hultman et al., "Microstructure evolution during the isostructural decomposition of TiAlN-A combined in-situ small angle X-ray scattering and phase field study," J. Appl. Phys. 113, 213518 (2013).
${ }^{5}$ L. Rogström, L. J. S. Johnson, M. P. Johansson, M. Ahlgren, L. Hultman, and M. Odén, "Age hardening in arc-evaporated ZrAlN thin films," Scr. Mater. 62, 739-741 (2010).

${ }^{6}$ L. Hultman, J. Bareño, A. Flink, H. Söderberg, K. Larsson, V. Petrova et al., "Interface structure in superhard TiN-SiN nanolaminates and nanocomposites: Film growth experiments and ab initio calculations," Phys. Rev. B 75, 155437 (2007)

${ }^{7}$ M. P. Johansson Jõesaar, N. Norrby, J. Ullbrand, R. M'Saoubi, and M. Odén, "Anisotropy effects on microstructure and properties in decomposed arc evaporated $\mathrm{Ti}_{1-\mathrm{x}} \mathrm{Al}_{\mathrm{x}} \mathrm{N}$ coatings during metal cutting," Surf. Coat. Technol. 235, 181-185 (2013).

${ }^{8}$ L. Rogström, N. Ghafoor, J. Schroeder, N. Schell, J. Birch, M. Ahlgren et al., "Thermal stability of wurtzite $\mathrm{Zr}_{1-\mathrm{x}} \mathrm{Al}_{\mathrm{x}} \mathrm{N}$ coatings studied by in situ high-energy x-ray diffraction during annealing," J. Appl. Phys. 118, 035309 (2015).

${ }^{9}$ J. Q. Zhu, A. Eriksson, N. Ghafoor, M. P. Johansson, J. Sjölén, L. Hultman et al., "Characterization of worn Ti-Si cathodes used for reactive cathodic arc evaporation," J. Vac. Sci. Technol., A 28, 347-353 (2010).

${ }^{10} \mathrm{~A}$. Anders, "Ion charge state distributions of vacuum arc plasmas: The origin of species," Phys. Rev. E 55, 969-981 (1997).

${ }^{11}$ J. Zhu, B. Syed, P. Polcik, G. Håkansson, M. Johansson-Jöesaar, M. Ahlgren et al., "Effects of the cathode grain size and substrate fixture movement on the evolution of arc evaporated $\mathrm{Cr}$-cathodes and $\mathrm{Cr}-\mathrm{N}$ coating synthesis," J. Vac. Sci. Technol., A 32, 021515 (2014).

${ }^{12}$ I. C. Schramm, M. P. Johansson Jõesaar, J. Jensen, F. Mücklich, and M. Odén, "Impact of nitrogen vacancies on the high temperature behavior of $\left(\mathrm{Ti}_{1-\mathrm{x}} \mathrm{Al}_{\mathrm{x}}\right) \mathrm{Ny}$ alloys," Acta Mater. 119, 218-228 (2016).

${ }^{13}$ M. Odén, J. Almer, and G. Håkansson, "The effects of bias voltage and annealing on the microstructure and residual stress of arc-evaporated Cr-N coatings," Surf. Coat. Technol. 120-121, 272-276 (1999).

${ }^{14}$ H. J. Kim and M. S. Joun, "Effects of deposition temperature and time on the surface characteristics of TiN-coated high-speed steel by arc ion plating," J. Mech. Sci. Technol. 21, 575-584 (2007).

${ }^{15}$ P. D. Swift, "Macroparticles in films deposited by steered cathodic arc," J. Phys. D: Appl. Phys. 29, 2025 (1996).

${ }^{16} \mathrm{M}$. Birkholz, Thin Film Analysis by X-Ray Scattering, 1st ed. (Wiley-VCH Verlag GmbH \& Co., Germany, 2006).

${ }^{17}$ W. G. Sloof, B. J. Kooi, R. Delhez, T. H. de Keijser, and E. J. Mittemeijer, "Diffraction analysis of nonuniform stresses in surface layers: Application to cracked TiN coatings chemically vapor deposited on Mo," J. Mater. Res. 11, 1440-1457 (1996).

${ }^{18}$ W. C. Oliver and G. M. Pharr, "An improved technique for determining hardness and elastic-modulus using load and displacement sensing indentation experiments," J. Mater. Res. 7, 1564-1583 (1992).

${ }^{19} \mathrm{M}$. Odén, J. Almer, G. Håkansson, and M. Olsson, "Microstructure-property relationships in arc-evaporated $\mathrm{Cr}-\mathrm{N}$ coatings," Thin Solid Films 377-378, 407-412 (2000).

${ }^{20} \mathrm{H}$. B. Michaelson, "The work function of the elements and its periodicity," J. Appl. Phys. 48, 4729-4733 (1977).

${ }^{21}$ H. Malamud and A. D. Krumbein, "Measurement of the effect of chlorine treatment on the work function of titanium and zirconium," J. Appl. Phys. 25, 591-592 (1954).

${ }^{22}$ E. W. J. Mitchell and J. W. Mitchell, "The work functions of copper, silver and aluminium," Proc. R. Soc. London, Ser. A Math. Phys. Sci. 210, 70-84 (1951).

${ }^{23}$ M. P. Marder, Condensed Matter Physics, 2nd ed. (John Wiley \& Sons, Inc., New Jersy, USA, 2010).

${ }^{24}$ A. Anders, E. M. Oks, G. Y. Yushkov, K. P. Savkin, I. G. Brown, and A. G. Nikolaev, "Measurements of the total ion flux from vacuum arc cathode spots," IEEE Trans. Plasma Sci. 33, 1532-1536 (2005).

${ }^{25}$ A. Anders and G. Y. Yushkov, "Angularly resolved measurements of ion energy of vacuum arc plasmas," Appl. Phys. Lett. 80, 2457-2459 (2002).

${ }^{26}$ J. E. Daalder, "Components of cathode erosion in vacuum arcs," J. Phys. D: Appl. Phys. 9, 2379 (1976).

${ }^{27}$ J. E. Hatch, Aluminum: Properties and Physical Metallurgy, 10th ed. (ASM International, USA, 1984).

${ }^{28}$ G. W a E W C R. Boyer, Materials Properties Handbook: Titanium Alloys (ASM International, USA, 1994).

${ }^{29}$ V. I. Kristya, "Analytical calculation of cathode spot parameters on the electrode surface in arc discharge," J. Surf. Invest.: X-Ray, Synchrotron Neutron Tech. 3, 289-291 (2009).

${ }^{30}$ S. A. Barengolts, D. L. Shmelev, and I. V. Uimanov, "Pre-explosion phenomena beneath the plasma of a vacuum arc cathode spot," IEEE Trans. Plasma Sci. 43, 2236-2240 (2015). 
${ }^{31}$ P. G. Slade, The Vacuum Interrupter: Theory, Design, and Application (CRC Press, 2007).

${ }^{32}$ T. Kubono, "A simplified analytical model for an anchored cathode root in a DC mercury vapour arc," J. Phys. D: Appl. Phys. 17, 1991 (1984).

${ }^{33} \mathrm{G}$. Eckhardt, "Properties of anchored cathode spots of a dc mercury vacuum arc," IEEE Trans. Plasma Sci. 8, 295-301 (1980).

${ }^{34}$ A. W. Hull, "A basic theory of the mercury cathode spot," J. Appl. Phys. 35, 490-496 (1964)

${ }^{35} \mathrm{~L}$. Tonks, "The force at an anchored cathode spot," Phys. Rev. 50, 226-233 (1936).

${ }^{36}$ U. R. Kattner, J.-C. Lin, and Y. A. Chang, "Thermodynamic assessment and calculation of the Ti-Al system," Metall. Trans. A 23, 2081-2090 (1992).

${ }^{37}$ V. T. Witusiewicz, A. A. Bondar, U. Hecht, S. Rex, and T. Y. Velikanova, "The Al-B-Nb-Ti system: III. Thermodynamic re-evaluation of the constituent binary system Al-Ti," J. Alloys Compd. 465, 64-77 (2008).

${ }^{38}$ V. F. Puchkarev and A. M. Murzakayev, "Current density and the cathode spot lifetime in a vacuum arc at threshold currents," J. Phys. D: Appl. Phys. 23, 26 (1990).

${ }^{39}$ R. Hackam, "Determination of the electric field enhancement factor and crater dimensions in aluminum from scanning electron micrographs," J. Appl. Phys. 45, 114-118 (1974).
${ }^{40}$ M. Adeli, S. H. Seyedein, M. R. Aboutalebi, M. Kobashi, and N. Kanetake, "A study on the combustion synthesis of titanium aluminide in the self-propagating mode," J. Alloys Compd. 497, 100-104 (2010).

${ }^{41}$ Y. Ma, Q. Fan, J. Zhang, J. Shi, G. Xiao, and M. Gu, "Microstructural evolution during self-propagating high-temperature synthesis of Ti-Al system," J. Wuhan Univ. Technol., Mater. Sci. Ed. 23, 381-385 (2008).

${ }^{42} \mathrm{H}$. Yan, F. Ai, and X. Chen, "Thermodynamics and kinetics of in-situ formation of TiAl3/7075 composites," J. Wuhan Univ. Technol., Mater. Sci. Ed. 28, 598-603 (2013).

${ }^{43}$ D. E. Alman, "Reactive sintering of $\mathrm{TiAl}-\mathrm{Ti}_{5} \mathrm{Si}_{3}$ in situ composites," Intermetallics 13, 572-579 (2005).

${ }^{44}$ R. W. Rice and W. J. McDonough, "Intrinsic volume changes of selfpropagating synthesis," J. Am. Ceram. Soc. 68, C-122-C-123 (1985).

${ }^{45} \mathrm{~K}$. I. Ibragimov and V. A. Korol'kov, "Temperature dependence of the work function of metals and binary alloys," Inorg. Mater. 37, 567-572 (2001).

${ }^{46}$ R. L. Boxman and S. Goldsmith, "Macroparticle contamination in cathodic arc coatings: Generation, transport and control," Surf. Coat. Technol. 52, 39-50 (1992).

${ }^{47}$ R. R. Zope and Y. Mishin, "Interatomic potentials for atomistic simulations of the Ti-Al system," Phys. Rev. B 68, 024102 (2003). 